\title{
The Relationship of Anxiety, School Burnout and Well-Being in High School Students
}

\author{
Ayu Andriyani ${ }^{1}$, Amirah Dzatul Himma ${ }^{1}$, Siti Asianty Alizar ${ }^{1}$, Zakki Nurul Amin ${ }^{1}$, \\ Mulawarman $^{1}$ \\ ${ }^{1}$ Guidance and Counseling Department Program, Faculty of Education, Universitas Negeri \\ Semarang, Sekaran, Gunungpati, Semarang City, Central Java, \\ Indonesia
}

\begin{abstract}
School as center of adolescent social life has an important role to help students to achieve well-being. But in fact, adolescence is often vulnerable to individual problems such as stress, anxiety, and self-destructive behavior. The current study examined the mediation effect of state and trait anxiety in the association between school burnout and well-being. State-Trait Anxiety Inventory (STAI), School Burnout Inventory (SBI), and Satisfaction with Life Scale (SWLS) was administered to 192 vocational high school students. Mediator analysis using bias corrected bootstrap method $\mathrm{N}=5000$ and $95 \%$ confidential interval on PROCESS software. The results show that school burnout as predictors on well-being students only indirectly via state and trait anxiety. These findings can be beneficial to our understanding of how and when state and trait anxiety impacts student's well-being, and have implication for development guidance and counseling programs to improve student's well-being.
\end{abstract}

Keywords: anxiety; school burnout; well-being

\section{INTRODUCTION}

Schools as center of adolescent social life have to pay attention for student's needs, both physically and psychologically [1, 2]. Well-being defined by Weisner as cited in Bornstein, Davidson, Keyes \& Moore [3] expressed as the achievement of the success of life characterized by the integration of physical, cognitive and socio-emotional functions. The integration of all aspects enables a person to have community role, meeting social relations needs, and able to address psychosocial and environmental issues.

As one of the factors that influence learning outcomes and developments, wellbeing has an important role for students [4]. Well-being is the student's ability to align demands from themselves and the environment characterized by positive affects (e.g. safe, peaceful, happy, happy). Well-being is also describe as student's satisfaction with themselves and their environment, which can help students to play an active role in school [5].

Allardt as cited in O'Brien [6] defines well-being as an individual condition enables to achieve satisfaction in fulfilling the basic needs that's is, having, loving and being. When applied in school, Allardt as cited in O'Brien [6] explained that school well-being as an students condition who achieve satisfaction in basic needs in schools, include the 
condition of school (having), social relations (loving), needs fulfillment (being) and health status in the school life. Student's well-being can improved academic outcomes, school attendance, prosocial behavior, convenience school, and school mental health [7].

Research of Josef and Hidayat [8] to 1,200 adolescents in Indonesia found that $4.6 \%$ of respondents experienced dissatisfaction with school, $65 \%$ of respondents had psychosocial and mental health problems in school, and one in eight students (12\%) had experienced physical attacks deliberately committed by other students. Problems faced by students both academic and non-academic often make students anxious and burnout in school.

Students experiencing school burnout display a lack of interest in class activities, recurrent absences, chronic tardiness, and irresponsible behaviors [9]. Furthermore, because of their sense of inadequacy they do not feel valued by teachers and frequently exhibit maladjusted behaviors at school with negative consequences for overall class atmosphere. Student burnout is a psychological syndrome caused by long-term exposure to school-related stress events and the pressure to achieve $[10,11]$.

While students with anxiety feelings will be worried in different number of situations. State and trait anxiety have been shown to interfere with cognitive functioning, to interfere with memory, lead to avoidance behaviors, and have some other effects $[12,13]$. Anxiety and school burnout are a lower risk factor for school involvement and poor school well-being, which in turn may increase anxiety symptoms. This findings research should make the teachers better able to cope with the growth detachment school students burn out can be one factor that can affect the welfare of students in school.

\section{METHODS}

\section{Procedure and Participant}

The sample was composed of Indonesian students $(\mathrm{N}=192)$ recruited at vocational high schools in the Semarang city (Indonesia). Participants ranged in age from 16 to 19, with a mean age of $17.5 \pm 0.85$. Gender distribution was 112 female $(57 \%)$ and 85 male $(43 \%)$. Students were recruited from two vocational high school. For those who agreed to participate in the research, will fill in a questionnaire that researchers have prepared. The measures were administered by trained researchers during school hours.

\section{Instrument}

Satisfaction with Life Scale (SWLS) developed by Diener, Emmnos, Larsen, \& Griffin [14] using was examined for well-being. Below are five statements (e.g., in most ways my life is close to my ideal). The statements that may agree or disagree are rated on a 7-point likert scale ranging from 1 'strongly disagree' to 7 'Strongly agree'. In the present study, instrument validity using product moment with score (0.553 - 0.831), and instrument reliability using Cronbach's alpha was respectively: 0.744 .

School burnout was examined using the School Burnout Inventory developed by Salmela-Aro et al. [15]. This instrument consists of nine items measuring three 
components of school burnout: (1) exhaustion at school (e.g., I feel overwhelmed by my schoolwork); (2) cynicism toward the meaning of school (e., I am not motivated to do my schoolwork and often think of giving up), and (3) sense of inadequacy at school (e.g., I often have feelings of inadequacy in relation to my schoolwork) to be rated on a 6 -point scale ( $1=$ strongly disagree; $6=$ strongly agree). Earlier studies have shown that it is possible to use both the total score for the nine items and the three separate scores for the subscales with score $r$ product moment $(0.440-0.653)$, and Cronbach's alpha was respectively: 0.677.

For anxiety was examined using State Trait-Anxiety Inventory (STAI) developed by Charles D. Spielberger et al. [16]. This instrument comprises 40 items measuring self-evaluation questionnaire state anxiety, 20 items (e.g., I feel calm), and trait anxiety, 20 items (e.g., I feel pleasant). Items are rated on a 4-point scale ranging from 1 'not at all' to 4 'very much so'. In the present study there are two invalid instruments that are "I feel strained" item and " I wish I could be as happy as others seem to be", instrument validity using product moment with score $r$ for state anxiety (0.464 - 0.721) and score $r$ for trait anxiety (0.354-0.634). Instrument reliability using Cronbach's alpha for state anxiety was respectively: 0.895, and 0.847 for trait anxiety.

The current research used back translation procedure before the data retrieval process. In order to validate the Indonesian versions of the SWLS, SBI, and STAI, both questionnaires were translated from English into Indonesian. For both scales, we followed the steps recommended in the scientific literature for the adaptation of evaluation instruments [17]. The translated items, back-translation of the items into English and comparison of the back translation and original questionnaire to inform a final optimum version in Indonesian.

\section{Data Analysis}

Correlations, means, and standard deviations were determined using IBM SPSS 22.0. Mediator analysis using corrected bootstrap method $\mathrm{N}=5000$ with $95 \%$ confidential interval in PROCESS software installed on IBM SPSS 22.0. This current research based on model 6 templates for PROCESS for SPSS and SAS by Andrew Hayes [18]. The conceptual model is presented in Figure 1.

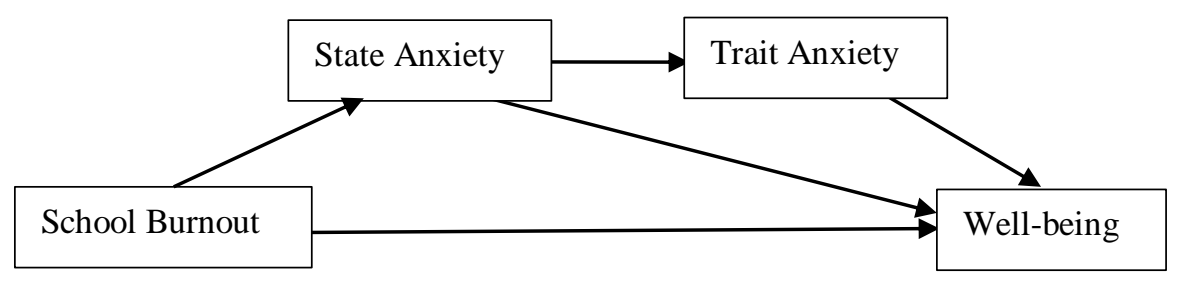

Figure 1. the conceptual model of well-being develop for testing in the study

\section{RESULT}

\section{Preliminary Analysis and Direct Effect Result}


The means, standard deviations, and zero-order correlations of all variables are listed in Table I. School burnout is not significant correlated with well-being, but positively correlated with state anxiety and trait anxiety. The direct effect result analysis of school burnout on well-being using PROCESS Hayes also showed insignificant results $(\beta=0,05 ; \mathrm{t}(188)=0,11 ; \mathrm{p}>0,05)$. In addition, well-being was negatively correlated with state anxiety and trait anxiety.

TABLE I. UNIVARIATE AND BIVARIATE STATISTICS FOR ALL STUDY VARIABLES.

\begin{tabular}{|l|c|c|c|c|c|c|c|}
\hline Variables & $M$ & & $S D$ & 1 & 2 & 3 & 4 \\
\hline 1. $S B$ & 28,62 & & 6.59 & - & & & \\
2. $S A$ & 38.70 & & 9.87 & $2.83^{* *}$ & - & \\
3. $T A$ & 43.34 & & 7.81 & $2.96^{* *}$ & $0.70^{* *}$ & - & \\
4. $W B$ & 22.08 & & 4.96 & -0.14 & $-0.40^{* *}$ & $-0,44^{* *}$ & - \\
\hline
\end{tabular}

Note: $\mathrm{N}=192 . \mathrm{SB}=$ School Burnout; $\mathrm{SA}=$ State Anxiety; TA: Trait Anxiety; WB= Well-being. $* \mathrm{p}<$ $0.05 ; * * \mathrm{p}<0.01$

\section{Testing for Mediation}

Relationship between school burnout on well-being significantly mediated by state and trait anxiety shown in Table 2. Furthermore, compared table 1 and table 2, and also direct effect result which indicates that school burnout have no direct effect on well-being, their relationship between school burnout in well-being is fully mediated by state and trait anxiety. Preacher and Hayes [19] explain that in full or complete mediation the effect of independent variables significantly on the dependent variable is fully mediated by the mediator variable.

TABLE 2. INDIRECT EFFECT OF SCHOOL BURNOUT ON WELL-BEING

\begin{tabular}{|c|c|c|c|c|}
\hline Total & $\beta$ & Boot SE & Boot LLCI & Boot ULCI \\
\hline Indirect 1 & -0.04 & -0.02 & -0.09 & -0.00 \\
Indirect 2 & -0.02 & -0.15 & -0.06 & -0.00 \\
Indirect 3 & -0.04 & -0.17 & -0.08 & -0.01 \\
\hline
\end{tabular}

Note: Indirect $1=$ school burnout on well-being through state anxiety. Indirect $2=$ school burnout on well-being through trait anxiety. Indirect $3=$ school burnout on well-being through state anxiety and trait anxiety

\section{DISCUSSION}

This current study shows that school burnout have not direct effect on student's well-being $(\beta=0,05 ; \mathrm{t}(188)=0,11 ; \mathrm{p}>0,05)$. This current finding explain that School burnout cannot be completely predictable student's well-being. In other hand, Salmela-Aro [15] suggests that school burnout will have direct effect on depressive symptoms, academic achievement, and school engagement.

But from these findings, it can be concluded that the relationship between school burnout on well-being can be predicted by involving a mediator variable. Anxiety here as a fully mediator with based on the comparison from direct and indirect effect 
in Tables 1 and 2, shows that state and trait anxiety significantly mediate the relations between school burnout and well-being. State and trait anxiety is fully mediated between the two variables, its meaning that school burnout can predict well-being only if involves anxiety.

Anxiety is a predictor of school burnout and well-being in general, as well as the school's well-being [14, 20, 21]. The student's well-being will be disrupted when they experiences a school burn-out caused by state or trait anxiety resulting from the surrounding situation. But if the students does not experience anxiety school burnout have no effect on student's well-being. So it can be conclude that school burnout and well-being is fully mediated by state and trait anxiety. This result can be used as a model to understand student's well-being comprehensively.

\section{CONCLUSION AND IMPLICATION}

This study provides an interesting results and model of school burnout, anxiety, and student's well-being in school. Results shows that school burnout have no direct effect on student's well-being. The both relationship is fully mediated by state and trait anxiety. Teachers and school practitioners need to pay attention to the third variable, one of which is anxiety that has been proven have indirect effect on school burnout and well-being.

These findings have implication for development guidance and counseling and also school programs to improve student's well-being. Counsellors should be able to prevent the causes can make the students burnout. In generally, teachers and counsellors need to develop school program that can improve student's well-being. They can providing new lessons and school services that can make students feel comfortable, save, and prosper at schools.

\section{REFERENCES}

[1] Gonzalez, M, F. Casas, and G. Coenders. 2007. "A Complexity Approach to Psychological WellBeing in Adolescence: Major Strengths and Methodological Issues" Soc Indic Res, 80:267-295.

[2] Petegem, K.V., A. Aelterman, H. V. Keer, Y. Rosseel. 2008. "The influence of student characteristics and interpersonal teacher behaviour in the classroom on student's wellbeing" Soc Indic Res, 85:279-291.

[3] Bornstein, M.H, L. Davidson, C. L.M. Keyes, and K. A. Moore. 2003. Well-Being: Positive Development Across the Life Course. Taylor \& Francis, pp. 235

[4] Frost, P. 2010. The effectiveness of Student Wellbeing Program and Service. Melbourne: Victorian Auditor-General's Report, pp. 123

[5] Karyani, U. et al. 2015. "The Dimensions of Student Well-being" in Seminar Psikologi \& Kemanusiaan. Psychology Forum UMM, ISBN: 978-979-796-324-8.

[6] O’Brien, M. 2008."Well-Being and Post Primary Schooling”. NCCA Research Report, 6. 18- 226

[7] Noble, T., H. McGrath, S. Roffey, and L. Rowling. 2008. A Scoping Study on Student Wellbeing. Canberra, ACT, Australia: Department of Education, Employment \& Workplace Relations

[8] Josef, F. M. \& R. Hidayat, R. 2011. Pokok-Pokok Temuan Survei Penjajagan Kebutuhan Pengembangan Karakter dan Kesehatan Mental Remaja. Yogyakarta: CPMH.

[9] Aypay, A. 2017. "A Positive Model for Reducing and Preventing School Burnout in High School Students” Educational Sciences: Theory \& Practice, 17(4):1217-1231. 
[10] Deasy, C, B. Coughlan, J. Pironom, D. Jourdan, and P.M McNamara. 2014. "Psychological Distress and Coping amongst Higher Education Students: A Mixed Method Enquiry" Plos One, 9(12): e115193.

[11] Schaufeli. 2002. "Burnout and engagement in university students: A Cross-National Study". Journal of Cross-Cultural Psychology, 33(5), 464-481.

[12] Spielberger, Charles D. 1966. Anxiety and Behavior. New York: Academic Press, pp.56.

[13] MacIntyre, P. D. and R.C. Gardner. 1991. "Investigating language class anxiety using the focused essay technique". Modern Language Journal, 75, 296-304.

[14] Diener, E., R.A. Emmons, R.J. Larsen., \& S. Griffin. 1985. "The Satisfaction with Life Scale" Journal of Personality Assessment, 49, 71-75.

[15] Salmela-Aro, K., N. Kiuru, E. Leskinen, and J.E. Nurmi. 2009. "School Burnout Inventory (SBI): Reliability and Validity" European Journal of Psychological Assessment, 25(1):48-57.

[16] Spielberger, C. D. 1977. Anxiety Current Trends in Theory and Research. London. Academic Press.

[17] Muñiz, J., \&D. Bartram. 2007. "Improving international tests and testing”. European Psychologist, 12:206-219.

[18] Hayes, A.F. 2013. Model templates for PROCESS for SPSS and SAS. The Guilford Press, pp. 9.

[19] Preacher, K. J and A.F. Hayes, 2004. "SPSS and SAS Procedures for Estimating Indirect Effects in Simple Mediation Models". Behavior Research Methods, Instruments, \& Computers, 36 (4), 717-731.

[20] Trudel, S.J, and S. Guay, and A. Marchand. 2009. "The relationship between social support, psychological stress and the risk of developing anxiety disorders in men and women: results of a national study" Can J Public Health, 100(2):148-52.

[21] Adeyemo, D. A and A.T. Adeleye. 2008. "Emotional Intelligence, Religiosity and Self-Efficacy as Predictors of Psychological Well-Being among Secondary School Adolescents in Ogbomoso, Nigeria" Europe's Journal of Psychology, 4(1). 